\title{
INSTITUTIONAL STRUCTURES FOR STUDENT-INCLUSIVITY IN QUALITY ASSURANCE PROMOTION IN HIGHER EDUCATION: THE CASE OF ONE UNIVERSITY IN ZIMBABWE
}

\author{
P. Nkala \\ National University of Science and Technology \\ Bulawayo, Zimbabwe \\ e-mail: pmasayina1966@gmail.com / https://orcid.org/0000-0002-2441-9856
}

\section{Ncube}

Gwanda State University \& IDS-National University of Science and Technology

Bulawayo, Zimbabwe

e-mail: mthumzilankatha@gmail.com / https://orcid.org/0000-0002-7178-5955

\section{ABSTRACT}

Researchers have investigated co-curricular and extracurricular activities associated with student learning and personal development but neglected exploring levels of students' involvement. IHLs oftentimes have no structures responsible for quality assurance (QA). Research should focus on specific structures, activities and the frequency of student involvement. Although Zimbabwe Council for Higher Education superintends over QA processes, it remains unclear which/how institutional structures foster student inclusivity in QA processes. Pragmatic research, marked by mixed methods was used to examine university QA structures for inclusivity. Science, Technology, Engineering and Mathematics IHLs were targeted and purposive sampling helped select 15 QA office(rs) and SRC in one STEM university. Primary data from questionnaires and key informant interviews were used. Structures governing IHLs are prescribed by Acts of Parliament and the current frequency of involvement depends on meetings scheduled for IHL structures. This constricts effective involvement. Minimal involvement occurs in prescribed structures although more satisfying involvement is in student-initiated social clubs and organisations. IHL legislative instruments should be amended to reflect diversity in higher education; allow university Councils to tailor-make IHL institutional/infrastructural structures to deliver on their mandates than rely on prescribed one size fits all. Such change will foster more satisfying involvement for student socioacademic success.

Keywords: institutional, structures, HEls, quality-assurance, student-inclusivity

\section{INTRODUCTION}

Institutional structures and their governance have become instructive for improving quality across components of higher education (Hénard and Mitterle 2010). Meanwhile, the attendant concept of quality assurance is rising globally with a view of balancing between institutional 
autonomy and their accountability (Hénard and Mitterle 2010). Scholars have argued that mechanisms are often in place although institutions tend not to systematically identify QA practices as such (Loukkola and Zhang 2010). They suggest many HEIs vary in structures that support QA implementation processes (Loukkola and Zhang 2010). While staff and students' participation is one of the key principles in developing a quality culture and QA processes, half the time HEI do not have a committee responsible for QA (Loukkola and Zhang 2010; Lanarès 2008). The need for accountability processes that uphold quality using internal and external actors is traceable to the mass enrolment among HEIs and the doubts concerning the possibility of maintaining quality and accountability (Loukkola and Zhang 2010). To that end, Hénard and Mitterle (2008) assure that accountability requires participation frameworks of stakeholders in governing bodies.

Higher education in Zimbabwe has roots in 1957 when the University College of Rhodesia and Nyasaland affiliated to the University of London (UCL) (Garwe 2014; Shizha 2011). Since then and following the massification of primary and secondary education, leading to increased demand for higher education, there are more than 15 universities in the country (Mohamedbhai 2008; Garwe 2014). Recent developments highlight show HEIs faced with triple constraints challenges from outside and within (Shava et al. 2016). Massification in higher education therefore raises very important and serious questions regarding quality control in higher education both inside and outside lecture rooms. Factors such as (i) the quality of students undertaking higher education, (ii) qualifications and experiences of lecturers in higher education institutions, (iii) the nature of the conductivity of the learning environment, (iv) distribution of teaching and learning resources, and (v) participation learners in quality assurance issues among others are investigated.

Previous attempts aimed at quality assurance have excluded and ignored the role of students as an unassuming stakeholder in the higher education industry. As a contribution to scholarship, this article seeks to (i) determine structures for student involvement in quality assurance and promotion and (ii) examine quality assurance structures for inclusivity of student as stakeholders using a case of one University in Zimbabwe. The following questions guided this study: (i) what structures exist for student involvement in quality assurance and promotion and (ii) how inclusive are quality assurance structures for students as stakeholders?

While in 1957 the University College of London (UCL) was responsible for ensuring the maintenance of quality and standards, that domain is the mandate of the Zimbabwe Council of Higher Education (ZimCHE) to ensure inclusivity (Garwe 2014; Shizha 2011). The term "inclusivity" in this article refers to the process of sharing decisions which affect student's teaching and learning life within their communities on and off campus. Inclusivity in modern 
education institutions helps build democracies and standards against which democracies are measured, begging the question, to what extent is the quality of education improvement approaches in universities democratic and inclusive?

Students as the key stakeholders of higher education have engaged in protests across Europe in the recent past to maintain the role of higher education as a public good with public responsibility that guarantees equal access and success (Bergan and Damian 2010; Ufert 2011). Arguments that as co-producers, students should be but are not involved in management of processes, yet were equally responsible for higher education management since higher education is designed for students, by and with them (Bergan and Damian 2010; Ufert 2011). On the converse, students are also the main beneficiaries of an increased quality of higher education, making them an indispensable stakeholder whose interests remain important. Students should have more impact in decision-making and governance of higher education (Tamrat 2020; Luescher-Mamashela 2013) which must be a community of students and professors who are equally responsible for its quality (Ufert 2011). Unfortunately, students are increasingly being viewed as passive customers, while the on-going inclusion of new external stakeholders, the new managerialism.

Student involvement comprises the active participation and passionate engagement of students in curricular, co-curricular and extra-curricular activities and interactions (Tamrat 2020; Astin 1984). The concept of student involvement was coined by Astin (1984) wherein he used the term for curricular and extracurricular domains. The achievement of learning outcomes defines the quality of education through describing what a student thinks, creates or does after going through a learning unit (Singh and Srivastava 2013). Besides, learning outcomes outline how a student develops during the learning process. For achieving a learning outcome, an institution designs various academic, co-curricular and extramural activities and invites its students to participate in them (Singh and Srivastava 2013). In turn, the students avail opportunities to develop themselves academically, socially, culturally and professionally displaying a varied degree of involvement in learning and development opportunities (Singh and Srivastava 2013;2015).

\section{The problem}

Developing country universities are yet to attach the accurate premium on research where the focus is on teaching and there is a dearth of education on the publication process among institutions of higher learning (IHL). Garwe (2015) Kusure et al. (2006) suggest few journals are locally available to publish articles hence students and lecturers have suffered lack of exposure to research and publication. Majoni (2014) blames low research output on 
unnecessarily high workloads and under funding by government, industry and IHLs. The scholar further argued that although QA has always been in place through peer review and student evaluation mechanisms, these are not being fully utilized due to lack of funds (Majoni 2014). Citing inadequate quality controls mechanisms, Majoni (2014) suggests funding challenges have hampered quality teaching and effective quality assurance systems in most universities.

There is need to determine QA structures to foster student involvement and examine their inclusivity as stakeholders. Tapera and Kuipa (2016) underscore the role of QA in ensuring IHL's relevance to industry while maintaining regional and global competitiveness in higher education. Their lamentation draws from similar expressions in Marock (2000), Dill (2007) and European Association for Quality Assurance in Higher Education (ENQA) (2009) who argue HEIs should ideally be centres of excellence in academic provision. Expectations from industry and communities stakeholders is that HEIs should produce high quality graduates, studentproducts with relevant knowledge, skills and expertise to provide innovative solutions to industry problems (Tapera and Kuipa 2016).

\section{REVIEW OF LITERATURE}

This section of the article looks at theoretical and empirical issues surrounding institutional structures fostering student involvement in HEI processes. Adopting a rights-based approach to education as this study does, is not a panacea (United Nations Children's Fund (UNICEF) 2007; Boesen and Martin 2007) as it has some challenges. Particularly, balancing claims of different rights holders and addressing potential tensions between the realization of different rights or between rights and responsibilities (UNICEF 2007; Boesen and Martin 2007). The notion of students as co-producers and consumers in HEIs poses the most challenges (UNICEF 2007)

Thus, the reviewed literature in this section sought to identify institutional structures for student-inclusivity in the promotion of QA in Zimbabwe's higher education. HEIs everywhere are obligated to reconsider their stakeholder relationships in terms of quality assurance (Jongbloed, Enders and Salerno 2008). The manner with which HEIs identify, prioritise, and engage with communities reflects evolution towards quality delivery (Jongbloed et al. 2008). Although Tanzania has significant progress towards internally and externally validated HEI quality assurance practices, more remains outstanding (Machumu and Kisanga 2014). By contrast, Botswana, Namibia, Lesotho, Nigeria and Kenya have practised programmatic accreditation and institutional registration/accreditation overseen by respective QA agencies (Adamu and Adamu 2012; Machumu and Kisanga 2014). 
In addition to that, in Ethiopia for example, higher education relevance and quality agency practise institutions participation of private HEIs and other stakeholders in the assessment of the status of QA in private HEIs systems (Kisanga 2014; Machumu and Kisanga 2014). The stakeholder involvement procedures for developing policies that establish QA systems and practices is the main HEIs' challenge (Mourkani and Shohoodi 2013). Empirical evidence shows that HEIs that actively engage students in academic, co-curricular, and extramural activities successfully promote and strengthen student learning and development. Highly engaged students are the best students of any institution (Singh and Srivastava 2015; Krause and Coates 2008; Kuh 2007; Limbu, Mukherjee and Gurung 2013). Traditionally, HEIs have used committee systems for a very long time for QA. Those with a longer history in QA emphasize student surveys, the feedback loop and informing the students about the follow-up of QA activities students participated in. Almarghani and Mijatovic (2017); Loukkola and Zhang (2010) suggest although the involvement of academic staff is systemic and common in all stages from curriculum design to involvement in formal QA processes, student involvement has not been as widespread among HEIs.

\section{Factors negatively affecting the quality of higher education in Zimbabwe}

The massification of higher education in Zimbabwe has precipitated challenges other than the economic meltdown that has dogged the country for almost three decades (Garwe 2015; Majoni 2014). Factors cited as having led to the deterioration of quality in higher education include (i) comparative lack of adequate investment in higher education, (ii) expansion of university student intakes and systems in general, (iii) diminishing government subsidies to higher education (HE) (iv) failure to balance widening and deepening access and the associated costs (Mhlanga 2008); (v) low salaries and poor working conditions leading to the brain drain especially in the mid-1990s through to 2010, (vi) the harsh political climate that led to persecution of teachers following the 2000 parliamentary elections, having allegedly supported opposition parties and (vi) archaic, primordial and anachronistic teaching and learning equipment. Less than proportional investment coupled with lacking basic provisions, shortages of equipment and other teaching and learning materials, and massification of higher education affected quantity and quality of graduates disparately. Such factors are unlikely to vanish, which calls for private and public universities in Zimbabwe to brace for inclusive mechanisms where students and graduates fit in employment sectors traditionally a preserve for university graduates (Majoni 2014).

\section{Brain drain on the quality of higher education in Zimbabwe}

Brain drain, marked by mass emigration of qualified and highly skilled staff caused serious 
staff shortages in most HEIs in Zimbabwe. This find expression in Mukwambo (2016); Mashininga (2010) who point to a Parliamentary Committee on Education that once reported the University of Zimbabwe departments of Animal Science, Community Medicine, Metallurgy and Clinical Pharmacology required 20,18, 13 and 11 lecturers respectively but those vacancies remained unfilled as there were no takers. They further note that the Computer Science and Veterinary Sciences, which required 13 lecturers but had one each while Psychiatry, Geoinformatics and Mining Engineering that required 16, 10 and 8 respectively had one lecturer each (Mukwambo 2016; Mashininga 2010). Medicine had 8 lectures in post instead of 26 while the anaesthetic, statistics, anatomy and haematology departments each had two lecturers instead of 16, 11, 10 and eight respectively (Mukwambo 2016; Mashininga 2010). Attempts to lure those that had left for the Diaspora were unsuccessful as the low salaries, lack of personal development prospects and poor working conditions that caused them to vote with their feet had not changed.

There is no doubt therefore that such staff shortages impact negatively on the quality of teaching and quality of graduates churned out by departments and faculties affected. The brain drain in higher education in Zimbabwe has caused the employment of less qualifies lecturers to handle particularly, postgraduate programmes. Such lecturers cannot lead their students from ignorance to knowledge especially at postgraduate level. Shava et al. (2016) argue that even where policies, programmes and processes to produce quality teachers are stated and specified, teaching teachers how to teach effectively is a complex process that has never been easy, hence the debate on quality teacher education and how best teachers can be produced.

\section{Quality control and the Zimbabwe Council for Higher Education (ZimCHE)}

The mandate of the ZimCHE is to ensure quality education in a context of increased student numbers against a background of limited and dwindling funding. Government, industry and commerce, professional bodies as well as parents and students demand higher levels of accountability on quality from universities. Inadvertently, as consumers of the outputs from universities stakeholders need to be protected from the ultimate lower academic standards and offerings by universities. The Zimbabwean government policy emphasizes more stringent quality assurance policies and arrangements in all local universities through the ZimCHE. Such QA bodies in higher education are not unique to Zimbabwe but exist in countries world over.

\section{Quality assurance promotion in higher education institutions}

Although the gist of what is meant by "quality" in higher education has long been debated (Harvey and Green 1993; Harvey and Williams 2010 cited in Scott 2018), according to 
government guidance, the purpose of "quality assurance" is to provide evidence that standards of teaching and learning are being met (BIS 2016, cited in Scott 2018). The Quality Assurance Agency (QAA) emphasized the need for evidence in their definition thus, "at its core, the purpose of QA is to be transparent and demonstrate quality in overt and measurable ways" (Barnes and Bohrer 2015, 63, cited in Scott 2018).

\section{The meaning of student-inclusivity in higher education}

Inclusivity in higher education means equally available and accessible education institutions and systems to every potential and current students, while respecting individual differences in physical and cognitive abilities, various social, cultural and religious backgrounds (Schuelka, Sherab and Nidup 2019; Ceresnova and Rollova 2018). Inclusivity in higher education, encompassing "universal accessibility to knowledge", refers also not necessarily to the needs of people with special educational needs, but to all learners, taking into consideration differing needs to achieve effective education for all (Porfírio, Martins, Gerardo 2016). Institutional structure inclusivity in quality assurance in this case means taking into account student's inputs into improving the quality of teaching and learning in STEM higher education institutions in Zimbabwe.

Gebrehiwot (2015); Fry, Ketteridge and Marshall (2009) underscore the importance of inclusivity through ensuring university buildings reflect HEI beliefs about learning and teaching and mirror concerns about inclusion, participation and community. QA agencies thus implore HEIs to enact structures and procedures wherein students can be involved as partners in QA and enhancement (QAA 2015, 12; cited in Scott 2018). They suggest HEIs should provide evidence of benefits that accrue from student involvement, regularly reviewing structures in the light of this (QAA 2015, 12; cited in Scott 2018). The Quality Assurance Agency (QAA)'s emphasis on evidence of structures for student involvement and reaction to the feedback generated has led to widespread use of formal methods, with Little et al. (2009), cited in Scott 2018) pointing to staff-student liaison committees as examples.

\section{METHODOLOGY}

At the philosophical level the study hinged on the pragmatic worldview whose demands in interpreting phenomena is detected by the need for both qualitative and quantitative approaches. Tashakkori and Teddlie (2003) and Creswell (2011) underscore the growing need for mixed methods research, arguing it facilitates holistic understanding of phenomena through providing balanced perspectives. Collecting data using semi-structured questionnaires with both open ended and closed ended questions, the study triangulated data collection methods through 
balancing views and perceptions to capture feelings among IHL stakeholders. Such data entailed integrated collection and analysis allowing inclusion of participants' views in openended questions. In this article, use was made of questionnaires on trends in student involvement for quality assurance and promotion among IHL that targeted quality assurance structures for sampling. Saunders (2012) and Saunders, Lewis and Thornhill (2016) present this view through the research onion that shows the layered methodological approaches used with this philosophy. The pragmatic mixed methods dovetail the research philosophy, approaches, strategy as well as data collection and analysis techniques and procedures used are espoused in the Figure 1 below adapted from Saunders (2012) and Saunders et al. (2016).

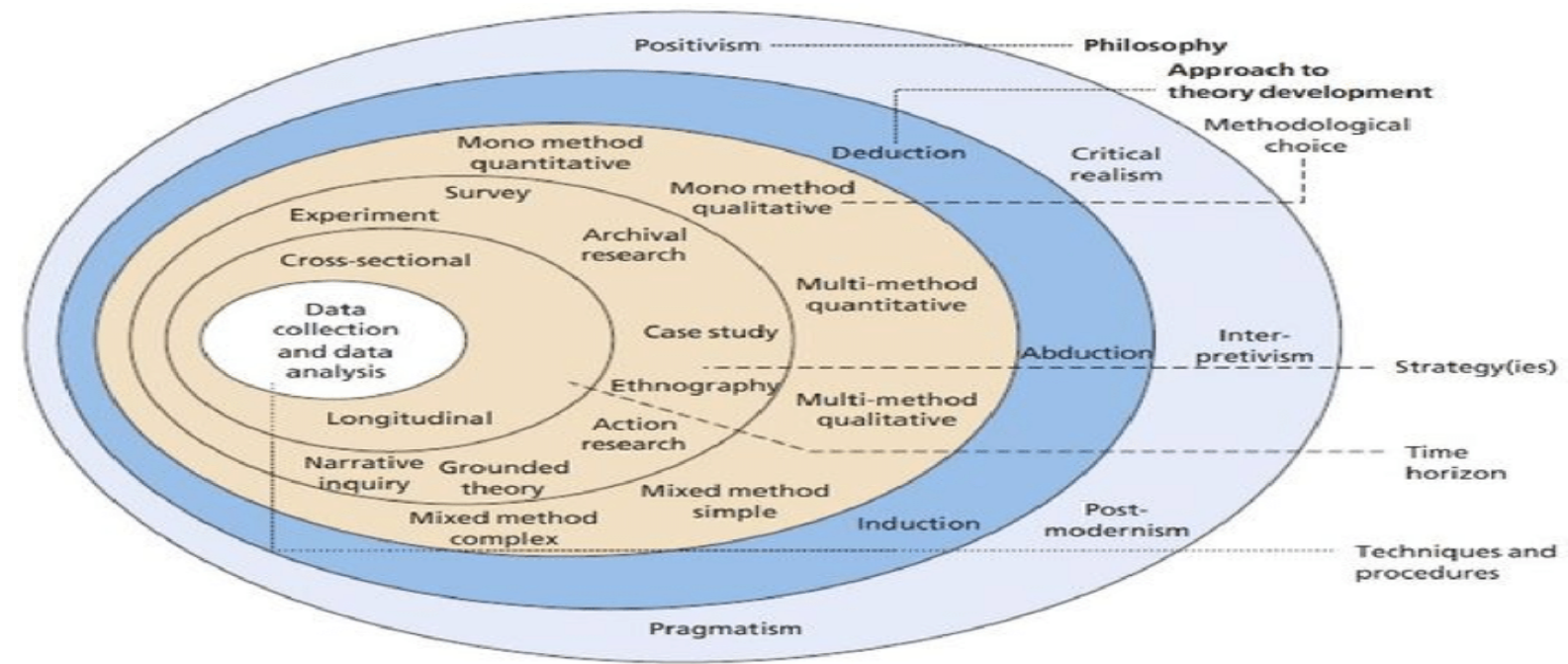

Figure 1: Research Onion (Source: Saunders 2012; Saunders et al. 2016)

\section{Target population}

Generally, the study targeted quality assurance managers from one institution of higher learning (IHL) in Zimbabwe whose mandate focuses on Science, Technology, Engineering, and Mathematics (STEM). The QA managers from this institution participated in the study given their proximity to the data sought. The questionnaire covered topics: (i) trends in STEM programming on practical teaching and learning, (ii) dominant methods of acquiring practical skills among STEM institutions in Zimbabwe, (iii) how regional STEM institutions have handled practical teaching and learning for student success, (iv) methods the IHL is using to foster student centred learning for academic success, (iv) biographical data and institutional background.

\section{FINDINGS}

Forty-seven percent of the respondents agreed that STEM programmes do blend and balance 
theory and practice. Most universities lack requisite infrastructure and 77 per cent of the respondents said university-industry field trips and visits as well as industrial attachments mitigate infrastructure shortage. Twenty percent of the respondents acknowledged the use of case studies as another strategy to complement infrastructure shortages. The pie chart results on the type of ladder of participation below shows that about 80 per cent of the student involvement was tokenism with student power comprising the remaining 20 per cent.

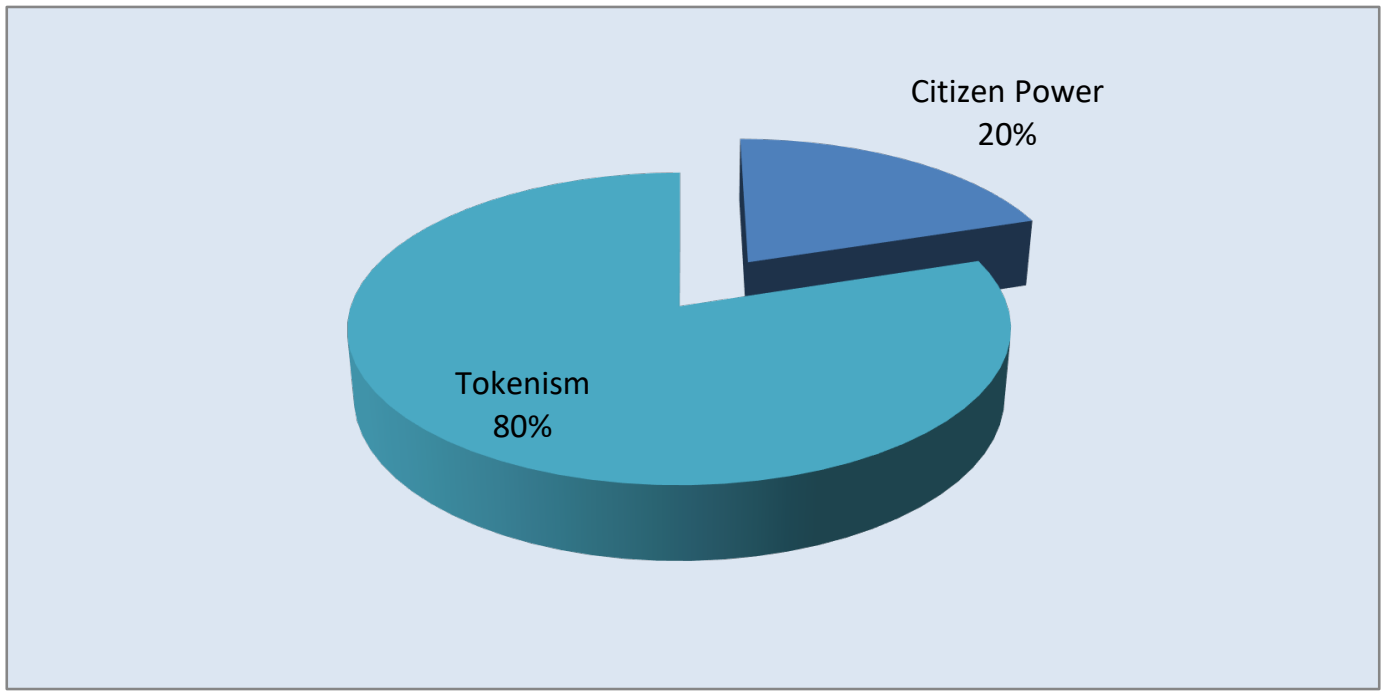

Figure 2: Nature of student participation in IHL quality assurance activities

Respondents said student involvement was impossible without compromise as response distributions in Figure 2 shows where the trend line shows the threshold of compromise that is dwarfed by responses to the affirmative represented by 10 respondents below. Students as rights-holders are short-changed at the hands of IHL duty-bearers through the various IHL quality assurance structures (Boesen and Martin 2007). There is evidence of too much variation of lower level forms of participation bordering on tokenism while IHL structures continue to dominate decision making on matters affecting students without involving the affected learners.

Figure 3 highlights responses that indicate IHL governance structures in Zimbabwe hold the view that involving students is impossible without change to compromise structural components, IHL functions and sharing decision making powers through change management. The trend line in Figure 3 stretches from 6 to 9 as the frequency trend against 10 respondents and 8 respondents who agree and strongly agree respectively accounting for cumulative 18 respondents vis-à-vis cumulative 12 respondents who "strongly disagreed" and "disagreed" respectively. Deducing from Figure 3, the trend line represents assertions by Luescher, Klemenčič and Mugume (2016) on the roles of university councils in ensuring the creation of structures for student involvement which is however ignored while only the explicitly stated 
functions are operationalised.

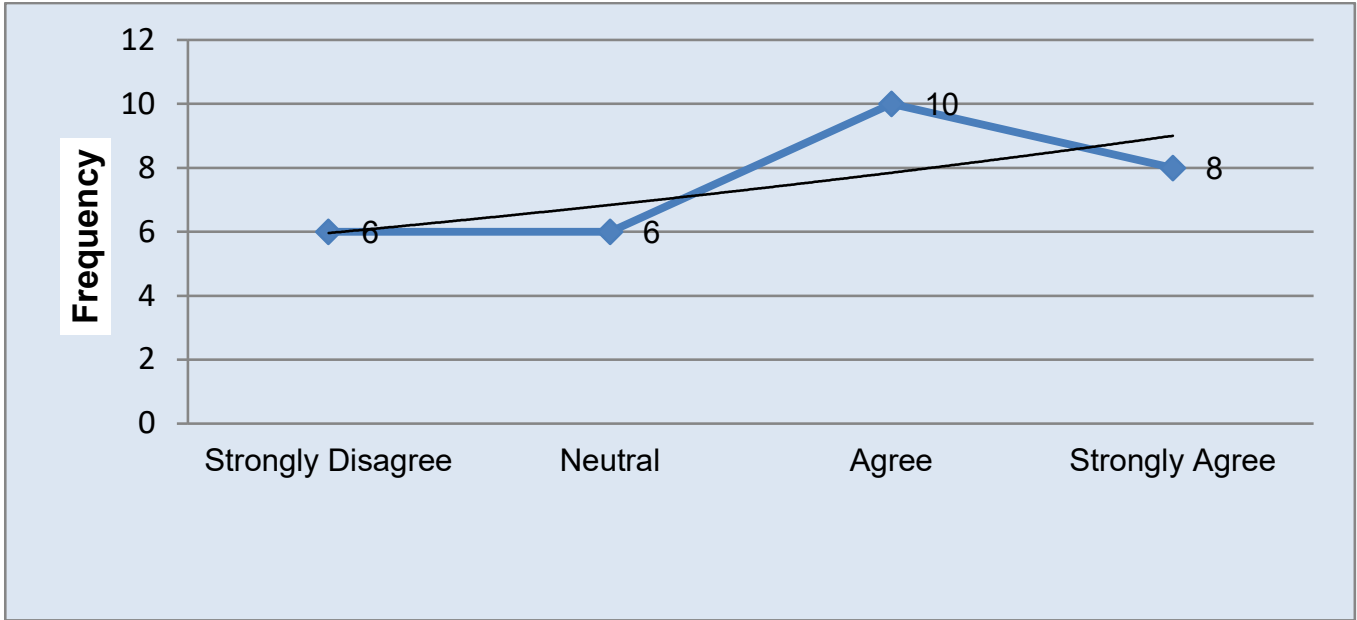

Figure 3: Student involvement impossible without compromise

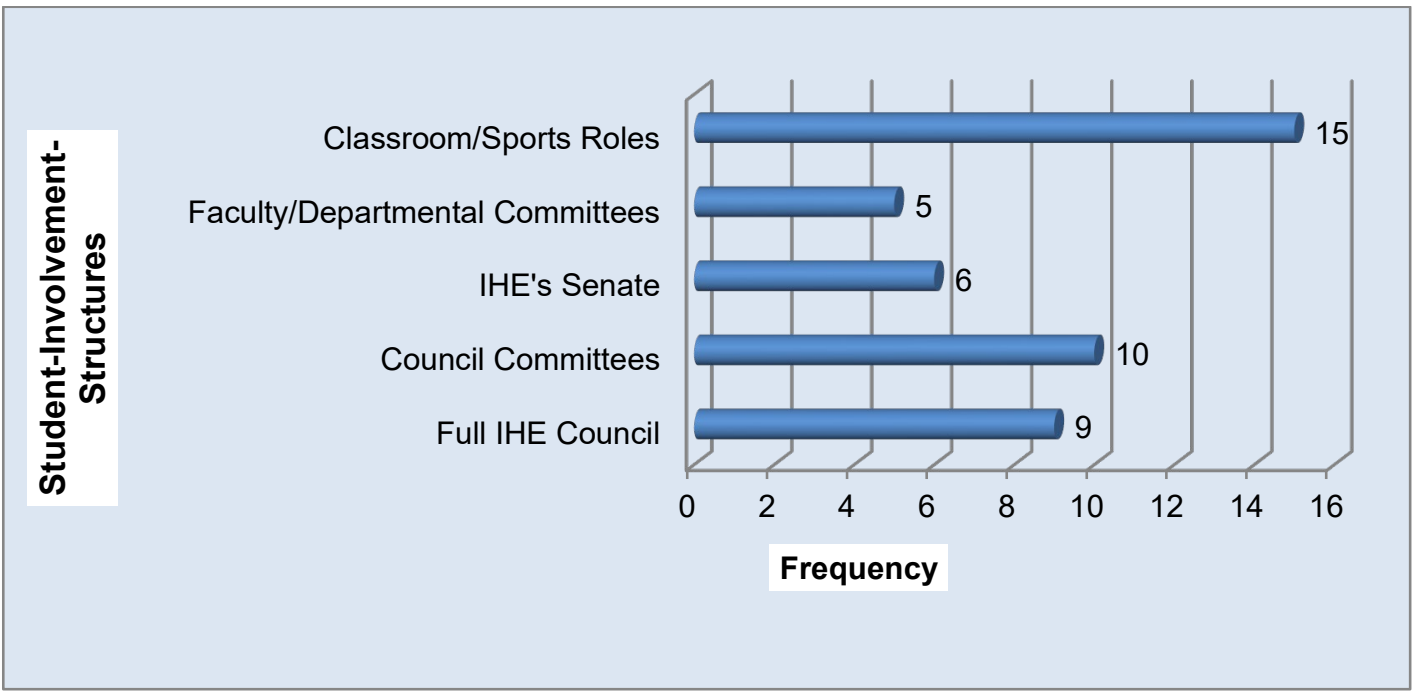

Figure 4: Quality assurance structures

Figure 4 shows the generic QA structures through which student involvement is promoted. These are largely accepted as "the" governance structures responsible for enforcing quality among IHLs. Responding to the question on what structures were in place to promote student involvement in quality assurance processes, the study established that the lecture/classroom and sports roles have always been the structures within which student participation has not been muzzled. Fifteen (15) respondents held the view students were limited to lecture rooms and sports. HEIs have limited student involvement promotion among quality assurance structures, with Council Committees and the Full IHL Council being the governance structures where there is guaranteed student representation rather than citizen control type of participation. Ten (10) 
and nine (9) respondents held the view on Council Committees and Full Committee.

What makes the guaranteed student involvement promotion in Council structures is the statutory provision and council exercises oversight over IHL management hence to be seen "doing things right" at the expense of doing the right things taking the centre stage. Consequently, any internal structure that promotes student involvement in quality assurance in the absence of Council membership and statutory provisions in structures such as Faculty and Departmental Boards is a constraint to quality assurance. This view is strengthened by the fact that even internally, the main structure involving students is the Senate, chaired by the Vice Chancellor, hence management seeks to be seen doing things right also ensures student are visible on such platforms yet not much effort is made at Faculty and Departmental Boards.

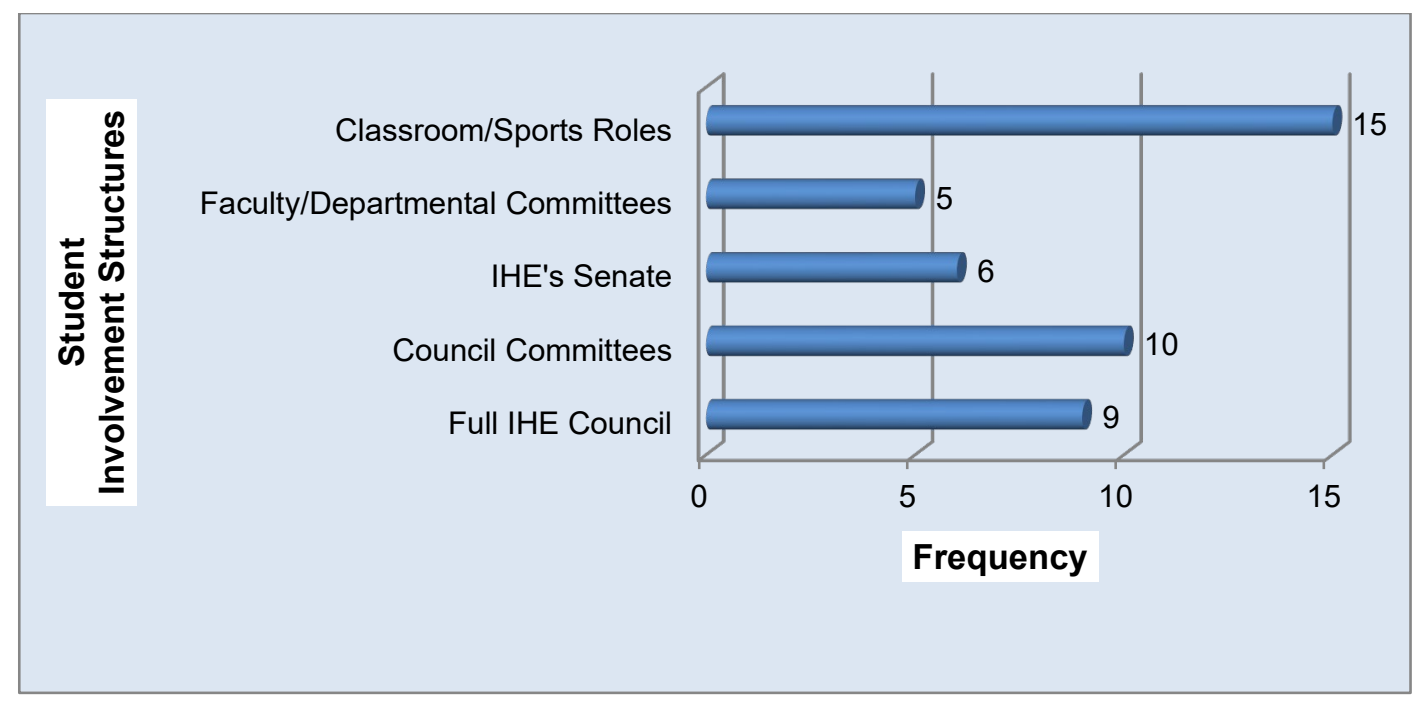

Figure 5: IHE-dominant quality assurance structures

Figure 5 shows the dominant structures that IHLs use to foster quality assurance and promote student involvement. Without doubt, the classroom (lecture-room) and sports roles (15 respondents) take the dominant role in fostering student involvement despite being non-core IHL business. This closely followed in succession by Council Committees (10 respondents) and the Full Council (9 respondents) and distantly, the IHL's Senate and Faculty/Departmental Committees (Boards) with six (6) and five (5) respectively. Dominance is marked by the unambiguous unison of choice of IHL structures. Clearly, the stakeholder influence also counts as the tendency to ensure student involvement in committees where the external evaluator, the Full Council and its Committees are conspicuous by their prominence.

Asked to tick against three the source of student inclusivity in IHL quality assurance structures, respondents confessed "IHL structural design", stemming from "IHL Act of 


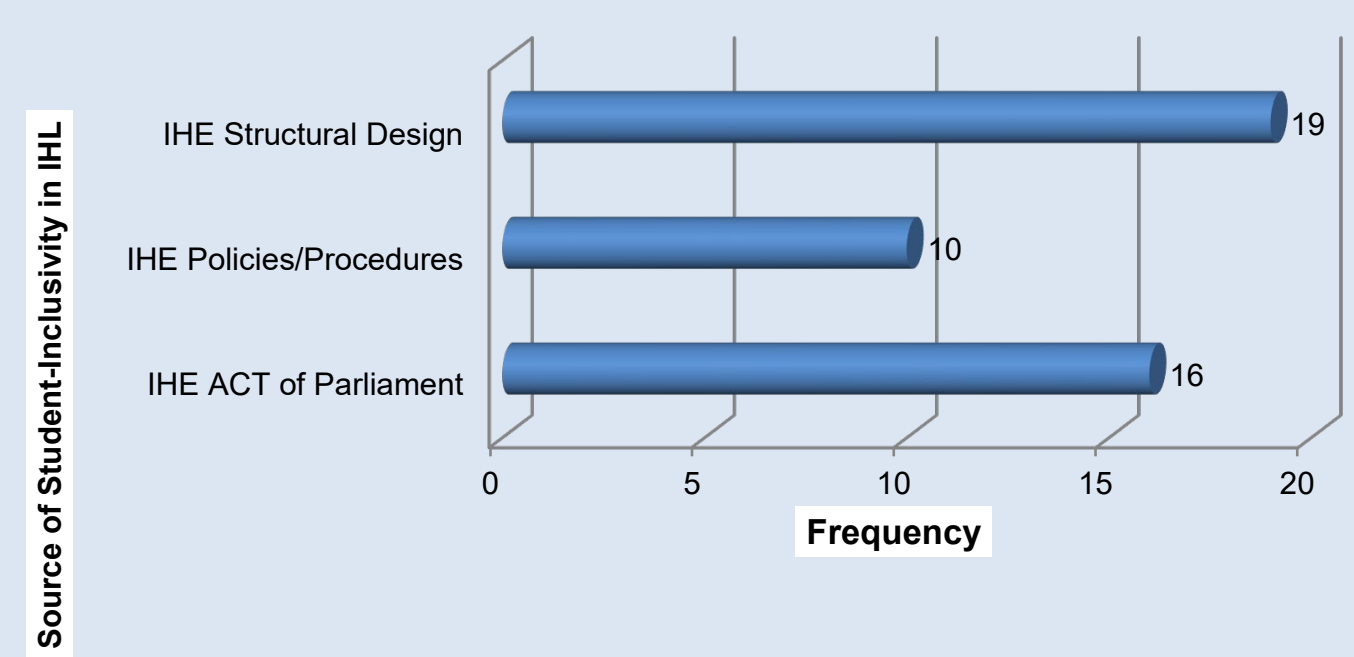

Figure 6: Source of student inclusivity in IHL quality assurance structures

Parliament". The study finds that there is rigidity in the legislation establishing IHLs, which is prescriptive and leaves little room for IHL Council and its Committees to innovate according to their circumstances. Above findings, corroborate findings by Bailey (2014) assertions that higher education governance structures, such as University Councils, quality assurance agencies or student loan board are often not explicitly legislated, even if there is provision for student representation (Bailey 2014 cited in Luescher et al. 2016). There is a tendency to legislate some and omit others although much variation exists across countries concerning explicit legislation of the extent of involvement of student representatives on institutional and sub-institutional levels of university governance (Bailey 2014, cited in Luescher et al. 2016). Respondents echoing this selected IHL Policies/Procedures as a last source of student involvement in quality assurance (10 respondents). The finding falls short of the expectation spelt by the Quality Assurance Agency (QAA) positing that such structures should be regularly reviewed (QAA 2015, 12; cited in Scott 2018). The emphasis by QAA on evidence for student involvement structures and response to the feedback generated highlights gaps where IHLs should advocate for such structures rather than rely on those established at inception through Acts of Parliament. The structures alluded to by Scott (2018) who underscores the QAA emphasis has led to the proliferation of formal student involvement methods while Little et al. (2009) cited in Scott (2018) underscore Staff-Student Liaison Committees.

Figure 7 shows the trend line that the "disagreed" and "strongly agreed" were clear that students indeed lost study-time attending quality assurance processes. The other responses comprised those who "strongly disagree" (2) and "agree" (2) respectively. Sentiments from 
respondents who strongly feel about an issue may not be as negligible in qualitative terms, especially depending on their level of influence in IHL and decision making therein.

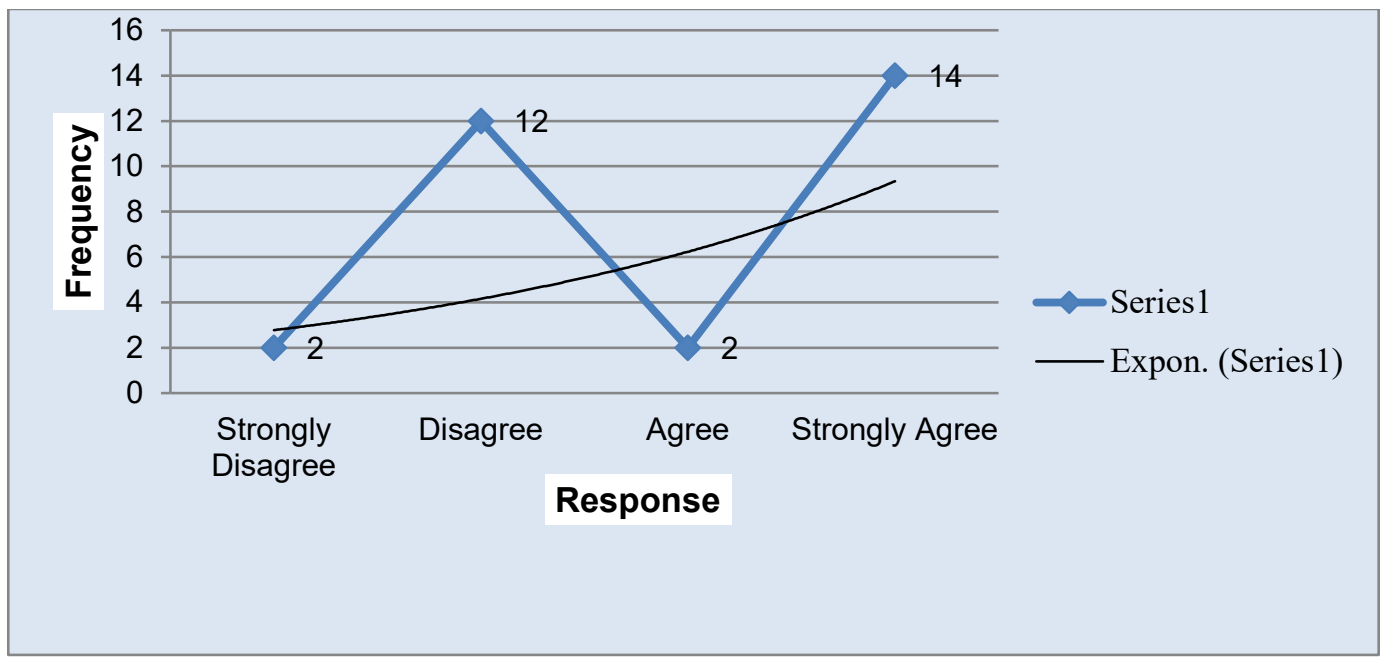

Figure 7: Students lose study-time attending Q-A processes

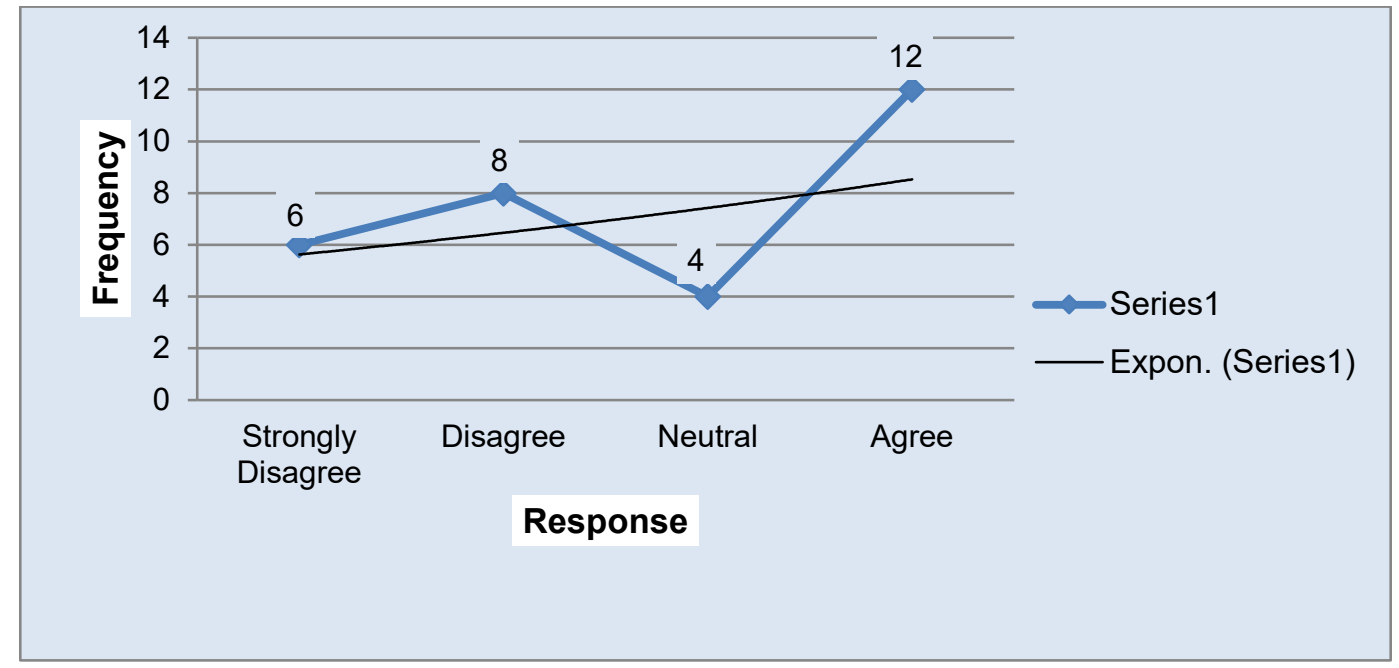

Figure 8: Lecturers lack skill/experience in taught subjects

The study established sentiments existed that lecturers lack requisite skills and or experience in taught subject areas. This is highlighted in a total response of 12 respondents who "agree" and combined 14 respondents comprising 8 who "disagree" and 6 who "strongly disagree" lecturers lack skills and experience. A spike in those who agree, which is four above the trend line is indicative of some reality in the finding. This is captured in text data where one senior respondent at an IHL lamented a culture of myopic recruitment. "We have a culture of recruiting our former students (Alumni) and that effectively rules out any innovation since we recycle ideas." 


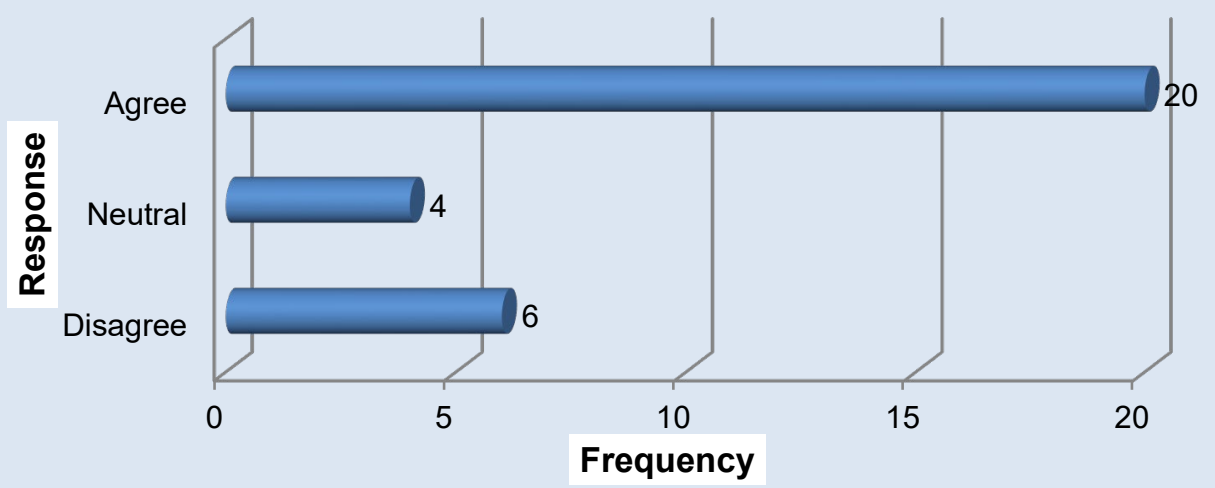

Figure 9: There is way too much theory than practice in STEM programmes

The study established that IHLs in the country tend to be treated as a homogenous lot by policymakers who prescribe quality assurance modalities disregarding diversity existing among different institutions. Quality assurance structures should be allowed to differ with regards the expected outcomes be they theory or practice and the nature of university council should be reflective of such expectations, the funding IHL receives must also reflect the mandate placed upon such IHL rather than use one size fits all approach to different institutions.

\section{CONCLUSIONS AND RECOMMENDATIONS}

There are inadequate facilities and structures for student involvement in assuring quality in higher education. Most quality assurance structures legislative creatures of Acts that established such HEIs, which leaves little room for diversification and regular review of mandates and deliverables. Student involvement suffers a stillborn fate without adequate funding and because the quality assurance agencies still demand evidence of student involvement, these are tailormade for evaluative reporting without deeper meaning to such involvement and participation. Consequently, resultant involvement is therapeutic in nature that short changes students both as duty-bearer stakeholders when involved through its Student Representative Council as part of management; and as rights holders when they are recipients of educational quality provided by the HEI.

We advance policy level recommendation that current HEI legislative instruments should be amended to reflect the diversity in higher education sector to allow university Councils to tailor-make structures of universities to deliver on their mandates rather than one size fits all. Future IHL Act of Parliament should help HEIs develop separate ethos and structures for 
student involvement and QA necessary to each HEI them rather than expect them to meet the same quality expectations. At implementation level, the IHL should be allowed to tailor-make programmes to satisfy all quality assurance elements they are answerable for to quality assurance agencies rather than be directed from a central position.

\section{REFERENCES}

Adamu, A. Y. and A. M. Addamu. 2012. Quality assurance in Ethiopian higher education: Procedures and practices. Procedia - Social and Behavioral Sciences 69: 838-846.

Almarghani, E. M. and I. Mijatovic. 2017. Factors affecting student engagement in HEIs - it is all about good teach. Journal Teaching in Higher Education: Critical Perspectives 22(8): 940-956.

Astin, A. 1984. Student involvement: A developmental theory for higher education. Journal of College Student Personnel 2(5): 297-307.

Bailey, T. 2014. The roles of national councils and commissions in African higher education system governance. Knowledge production and contradictory functions in African higher education, 171202.

Barnes, H. and J. Bohrer. 2015. Engaging professionally: Who does quality? In Professional life in modern British higher education, ed. B. Cunningham, 61-75. London: Institute of Education Press.

Bergan, S. and R. Damian. 2010. Higher education for modern societies: Competences and values (Vol. 15). Council of Europe.

BIS. 2016. Success as a knowledge economy. London: Department for Business Innovation and Skills.

Boesen, J. K. and T. Martin. 2007. Applying a rights-based approach: An inspirational guide for civil society. Danish Institute for Human Rights.

Ceresnova, Z. and L. Rollova. 2018. Case studies of inclusive higher education in Norway, Sweden and Slovakia. In International Conference on Applied Human Factors and Ergonomics, 312-323. Springer, Cham.

Creswell J. W. 2011. Controversies in mixed methods research. Thousand Oaks, CA: Sage.

Dill, D. D. 2007. Quality assurance in higher education: Practices and issues. The $3^{\text {rd }}$, International Encyclopaedia of Education. Elsevier Publications.

ENQA see European Association for Quality Assurance in Higher Education

European Association for Quality Assurance in Higher Education. 2009. Standards and guidelines for quality assurance in the European higher education area. $3^{\text {rd }}$ Edition. Helsinki.

Fry, H., S. Ketteridge and S. Marshall. 2009. A handbook for teaching and learning in higher education enhancing academic practice. $3^{\text {rd }}$ edition. New York: Routledge.

Garwe, E. C. 2015. Obstacles to research and publication in Zimbabwean higher education institutions: A case study of the research and intellectual expo. International Research in Education, 2015, Vol. 3, No. 1, 119-138.

Garwe, E. C. 2014. Quality Assurance Challenges and Opportunities Faced by Private Universities in Zimbabwe. Journal of Case Studies in Education, 5.

Gebrehiwot, Y. G. 2015. Towards more inclusive university curricula: the learning experiences of visually impaired students in higher education institutions of Ethiopia. Doctoral dissertation.

Harvey, L. and J. Williams. 2010. Fifteen years of quality in higher education. Quality in Higher Education 16(1): 3-36.

Harvey, L. and D. Green. 1993. Defining quality. Assessment and Evaluation in Higher Education 18(1): 9-34. 
Hénard, F. and A. Mitterle. 2008. Governance and quality in higher education. Education program on institutional management in higher education. France: OECD.

Hénard, F. and A. Mitterle. 2010. Governance and quality guidelines in higher education. A review of governance arrangements and quality assurance. Berlin: OECD.

Jongbloed, B., J. Enders and C. Salerno. 2008. Higher education and its communities: Interconnections, interdependencies and a research agenda. Higher Education 56: 303-324. DOI 10.1007/s10734008-9128-2.

Kisanga, H.J.M.S.H. 2014. Quality assurance practices in higher education institutions: Lesson from Africa. Quality Assurance, 5(16).

Krause, K. L. and H. Coates. 2008. Students' engagement in first-year university. Assessment \& Evaluation in Higher Education 33(5): 493-505.

Kuh, G. D. 2007. How to help students achieve. Chronicle of Higher Education 53(41): B12-B13.

Kusure, L. P., L. Mutanda, D. Mawere and L. Dhliwayo. 2006. Factors influencing research productivity among lectures in teachers' colleges in Zimbabwe. Southern Africa Journal of Education, Science and Technology 1(2).

Lanarès, J. 2008. Developing a quality culture. In EUA Bologna handbook, C 2.1-1. Brussels/Berlin, EUA/Raabe.

Luescher, T. M., M. Klemenčič and J. O. Jowi. 2016. Student politics in Africa: Representation and activism. African Minds Higher Education Dynamics Series Vol. 2. Africa Minds.

Luescher-Mamashela, T. M. 2013. Student representation in university decision making: Good reasons, a new lens? Studies in Higher Education 38(10): 1442-1456. http://dx.doi.org/10.1080/03075079.2011.625496

Limbu, Y. B., A. Mukherjee and B. Gurung. 2013. Student engagement techniques and teaching quality ratings in marketing education. Challenging the Bounds of Marketing Thought, 283.

Little, B., W. Locke, A. Scesa and R. Williams. 2009. Report to HEFCE on student engagement. London: Centre for Higher Education Research and Information.

Loukkola, T. and T. Zhang. 2010. Examining quality culture. Part 1-Quality assurance processes in higher education institutions. The European University Association.

Machumu, H. J. and S. H. Kisanga. 2014. Quality assurance practices in higher education institutions: Lesson from Africa. Journal of Education and Practice 5(6): 144-156.

Majoni C. 2014. Challenges facing university education in Zimbabwe. Greener Journal of Education and Training Studies 2(1): 020-024.

Marock, C. 2000. Quality assurance in higher education: The role and approach of professional bodies and SETAs to quality assurance. Council on Higher Education (CHE). http://www.che.ac.za (Accessed 7 November 2016).

Mashininga, K. 2010. "ZIMBABWE: Scores of 'Illegal' Private Colleges Closed." University World News July 18, No. 58.

Mhlanga, E. 2008. Quality assurance in higher education in Southern Africa: The case of the Universities of the Witwatersrand, Zimbabwe and Botswana Ephraim Mhlanga. Unpublished PhD Thesis, University of the Witwatersrand.

Mohamedbhai, G. 2008. The effects of massification on higher education in Africa, 20-24. Association of African University Press.

Morley, L. 2003. Quality and power in higher education. Buckingham: Society for Research into Higher Education and Open University Press.

Mourkani, G. S. and M. Shohoodi. 2013. Quality assurance in higher education: Combining internal evaluation and importance-performance analysis models. Middle-East Journal of Scientific Research 15(5): 643-651.

Mukwambo, P. 2016. Quality as human development: A case study of teaching and learning in 
Zimbabwean universities. Doctoral dissertation, University of the Free State.

Porfírio, J. A., M. Martins and G. Gerardo. 2016. Innovation and social learning in higher education. ISOLearn 6. http://www.isolearn.net/

QAA see Quality Assurance Agency.

Quality Assurance Agency. 2015. UK quality code for higher education, Part B: Assuring and enhancing academic quality. Chapter B5: Student Engagement. Gloucester: Quality Assurance Agency.

Saunders, M. N. 2012. Choosing research participants. Qualitative organizational research: Core methods and current challenges, 35-52.

Saunders, M., P. Lewis and A. Thornhill. 2016. Research methods for business students. Journal of Futures Studies 44. Pearson Education Limited, England.

Schuelka, M. J., K. Sherab and T. Y. Nidup. 2019. Gross national happiness, British values, and noncognitive skills: The role and perspective of teachers in Bhutan and England. Educational Review 71(6): 748-766.

Scott, E. A. 2018. Student involvement in quality assurance in HE in FE: Perceptions of students, teachers and managers. Doctoral dissertation, UCL (University College London).

Shava, G. N., D. Nkengbeza, M. L. Ntabi and E. L. Maemeko. 2016. Challenges of achieving quality teacher education: The case of secondary teacher education colleges in Zimbabwe. International Journal of Innovative and Applied Research 4(6): 35-44.

Shizha, E. 2011. Neoliberal globalisation, science education and African indigenous knowledges. In Critical perspectives on neoliberal globalization, development and education in Africa and Asia, 15-31. Sense Publishers.

Singh, A. K., S. Srivastava. 2013. Certain antecedents and consequence of student engagement in an Indian management education setting. Metamorphosis: A Journal of Management Research 12(1): $47-64$.

Singh, A. K. and S. Srivastava. 2015. Promoting student engagement in higher' education institutions. University News 52(52): December 29, 2014 to January 04, 2015. https://www.researchgate. net/publication/279197286

Tamrat, W. 2020. The exigencies of student participation in university governance: Lip services and bottlenecks. Higher Education Quarterly 74(1): 35-47.

Tapera, J. and P. K. Kuipa. 2016. Promoting quality assurance in Zimbabwean higher education institutions: Concepts, systems and processes. https://www.researchgate.net/publication/ 311186790

Tashakkori, A, and C. Teddlie. 2003. Handbook of mixed methods in social and behavioral research. Thousand Oaks, CA: Sage.

Ufert, K. 2011. No student left out - The do's \& don'ts of student participation in higher education decision-making. The European Students' Union.

UNICEF see United Nations Children's Fund.

United Nations Children's Fund. 2007. A human rights-based approach to education. United Nations Children's Fund / United Nations Educational, Scientific and Cultural Organization. 